\title{
A case-cohort study of human herpesvirus 8 seropositivity and incident prostate cancer in Tobago
}

\author{
Alicia C McDonald ${ }^{1}$, Frank J Jenkins ${ }^{2,4}$, Clareann H Bunker ${ }^{3,4}$, John W Wilson ${ }^{5}$, Alan L Patrick ${ }^{6}$ and \\ Joel $L$ Weissfeld $d^{3,4^{*}}$
}

\begin{abstract}
Background: We previously reported a cross-sectional association between the presence of human herpesvirus 8 (HHV-8) serum antibodies and screen-detected prostate cancer in men living in Tobago. In the same study population, we examined the association between HHV-8 seropositivity and incident prostate cancer discovered at later screenings.

Methods: In 40-81 year-old men without prostate cancer discovered at initial digital rectal examination (DRE) and prostate-specific antigen (PSA) screening, a case-cohort design measured the association between baseline HHV-8 seropositivity (modified immunofluorescence assay for antibodies against HHV-8 lytic antigens) and incident prostate cancer detected at DRE and PSA screenings three or five years later.

Results: Analyses included 486 unique individuals, 96 incident prostate cancer cases, and 415 randomly selected subjects representing an at-risk cohort. By design, the random sub-cohort contained 25 incident prostate cancer cases. In the sub-cohort, the frequency of HHV-8 seropositivity increased across age groupings (40-49 years: $3.5 \%$, 50-59 years: $13.6 \%$, and $\geq 60$ years: $22.9 \%$ ). HHV-8 seropositivity was higher in men with elevated ( $\geq 4.0 \mathrm{ng} / \mathrm{mL})$ than men with non-elevated PSA at initial screening (30.4\% vs. 9.9\% seropositive; crude odds ratio (OR) 3.96, 95\% confidence interval (Cl) 1.53-10.2; age-adjusted OR 2.42, 95\% Cl 0.91-6.47). HHV-8 seropositivity did not increase incident prostate cancer risk (age-adjusted hazard ratio (HR) 0.88, 95\% Cl 0.46-1.69).

Conclusions: Case-cohort analysis did not identify association between HHV-8 seropositivity and incident prostate cancer. However, analyses uncovered possible association between HHV-8 and PSA (a marker of prostate inflammation). Co-occurrence of HHV-8 seropositivity and PSA elevation may explain cross-sectional association between HHV-8 and PSA screen-detected prostate cancer.
\end{abstract}

Keywords: human herpesvirus 8, prostate cancer, case-cohort design

\section{Background}

In 2008, prostate cancer was the fifth most common cancer and the sixth leading cause of cancer death among men worldwide [1]. Men of African descent experience higher prostate cancer incidence and mortality than any other racial group [1-5]. Other accepted risk factors include older age and family history. The otherwise poor understanding of prostate cancer

\footnotetext{
* Correspondence: jwepid@pitt.edu

${ }^{3}$ Department of Epidemiology, University of Pittsburgh, A542 Crabtree Hall,

130 DeSoto Street, Pittsburgh, Pennsylvania, 15261, USA

Full list of author information is available at the end of the article
}

etiology motivates search for specific causal agents. Though not consistently [6], studies find prostate cancer in association with infectious disease agents, including Neisseria gonorrhoeae, Chlamydia trachomatis, human papillomavirus (HPV) type 18, and Treponema pallidum (syphilis) [7-11]. Other studies find viral DNA or evidence of viral gene expression in prostate tissues (HPV, human herpes simplex virus type 2, cytomegalovirus, Epstein-Barr virus, and human herpesvirus 8 (HHV-8) [10,12-19]), stromal fibroblasts within prostate tumors (xenotropic murine leukemia virus-related virus or XMRV [20]), or malignant prostate epithelial cells

\section{() Biomed Central}


(XMRV [21]). These infectious agents may elicit an immune response creating a cytokine tissue environment that leads to chronic inflammation, DNA damage, cellular proliferation, angiogenesis, and ultimately prostate cancer $[10,13,22,23]$.

HHV-8, a DNA virus, causes Kaposi's sarcoma and primary effusion lymphoma. In a high prostate cancer risk cohort of African-Caribbean men living on Tobago $[24,25]$, we found an association between HHV-8 seropositivity and prostate cancer discovered as a result of an initial prostate cancer screening (odds ratio [OR] 2.24, 95\% confidence interval [CI] 1.29-3.90) [9]. Four studies completed later in other population settings could not confirm an association between HHV-8 and prostate cancer $[6,11,26,27]$. Therefore, our current study re-examines this association in our Tobago study population, through consideration of the association between HHV-8 seropositivity and prostate cancer discovered, not as a result of the initial screening, but later as a result of subsequent screenings.

\section{Methods}

\section{Study Population}

The Tobago Prostate Survey is an ongoing populationbased longitudinal study of prostate cancer screening, as well as risk, in $\geq 40$ year-old men living in Tobago [24]. Tobago is a small Caribbean island, 7 by 26 miles in size, with 8078 40-79 year-old men, according to a 2000 census [28]. The population as a whole is $89 \%$ African or Black and $7 \%$ mixed heritage by nationality or ethnicity [28]. Identification of study participants occurred through the agency of posters, flyers, public service announcements, public presentations, healthcare workers, private physicians, and word of mouth [24]. Prostate cancer screening occurred in three waves, Wave 1 October 1997 to August 2003, Wave 2 - February 1999 to August 2003, and Wave 3 - May 2004 to March 2007. Although an open cohort, this report included only men screened at Wave 1 and subsequently rescreened at Waves 2 and/or 3 . Study procedures included risk factor questionnaires, blood collections, and prostate cancer screening examinations, with prostate specific antigen (PSA) serum concentrations $\geq 4$ $\mathrm{ng} / \mathrm{mL}$ or abnormal digital rectal examinations (DRE) prompting referral for ultrasound-guided trans-rectal prostate biopsy [24].

Wave 1 enrolled 3264 40-81 year-old men (97\% selfreporting African descent). The current study excluded men missing Wave 1 PSA $(\mathrm{n}=283)$, men with Wave 1 PSA $\geq 4.0 \mathrm{ng} / \mathrm{mL}$ not followed by prostate biopsy $(\mathrm{n}=$ 104), and men with prostate cancer detected at Wave 1 $(\mathrm{n}=330$ ), thereby leaving 2547 men at risk for prostate cancer at Wave 2 or Wave 3 (Figure 1). The study design excluded 756 at-risk men, including 633 at-risk men without subsequent PSA at either Wave 2 or Wave 3, 108 men with a Wave 2 or Wave 3 PSA $\geq 4.0 \mathrm{ng} / \mathrm{mL}$ not followed by biopsy, and 15 men with a prostate cancer negative Wave 2 biopsy, but no Wave 3 biopsy for Wave 3 PSA $\geq 4.0 \mathrm{ng} / \mathrm{mL}$ associated with $\geq 1.0 \mathrm{ng} / \mathrm{mL}$ PSA increase between Waves 2 and 3 (Figure 1). In the remaining 1791 at-risk men, a Wave 2 or Wave 3 biopsy completed before study closure (August 15, 2007) detected prostate cancer in 109 (Figure 1).

To measure the association between Wave $1 \mathrm{HHV}-8$ seropositivity and prostate cancer detection from a Wave 2 or Wave 3 screening, we used a case-cohort study design that compared prostate cancer cases at Wave 2 or Wave 3 ( $\mathrm{n}=109$; Gleason $6-49 \%$, Gleason 7 - 45\%, Gleason 8 or 9 - 6\%; pre-diagnostic screening PSA, mean $9.5 \mathrm{ng} / \mathrm{mL}$, median $4.4 \mathrm{ng} / \mathrm{mL}$ ) against a control group constructed as a simple random sample $(\mathrm{n}=442)$ of the 1791 at-risk men screened for prostate cancer at Wave 2 or Wave 3 . We used a case-cohort design because research costs prohibited determination of the HHV-8 status of all 1791 men in the at-risk group. As a result of the random selection procedure, 27 case men with prostate cancer at Wave 2 or Wave 3 entered the sub-cohort and contributed data as controls (Figure 1). The 442 and 1349 randomly selected and excluded men were statistically similar with respect to age, education, marital status, prostate cancer family history, history of smoking, personal history of cancer, history of benign prostatic hypertrophy, and Wave 1 PSA and DRE results. The 442 men selected for the subcohort survived a median 4.9 years $\left(5^{\text {th }}-95^{\text {th }}\right.$ percentile 1.7-6.8 years) between Wave 1 and the last complete post-Wave 1 visit. For the 109 cases, a median 7.2 months $\left(25^{\text {th }}-75^{\text {th }}\right.$ percentile $2.5-13.8$ months $)$ elapsed between pre-diagnostic screening and confirmatory biopsy.

Study participants signed an informed consent approved by the Institutional Review Boards of the Tobago Division of Health and Social Services and the University of Pittsburgh.

\section{Laboratory Methods}

Laboratory assays used frozen serum samples (thawed once and never re-frozen) stored temporarily in a $-20^{\circ} \mathrm{C}$ freezer at the Tobago Health Studies office in Scarborough, Tobago, and stored later in a $-80^{\circ} \mathrm{C}$ freezer at the University of Pittsburgh, Department of Epidemiology. PSA measurements used either Abbott Diagnostics $\operatorname{AxSYM}^{\circledR}$ or Siemens Healthcare Diagnostics ADVIA Centaur $^{\circledR}$ immunoassays. To detect serum antibodies against HHV-8 lytic antigens, an indirect immunofluorescence assay, as described elsewhere [29], used BCBL-1 cells containing the HHV-8 genome with a modified Rta gene inducible by doxycyclin [30]. Targeting fixed and 


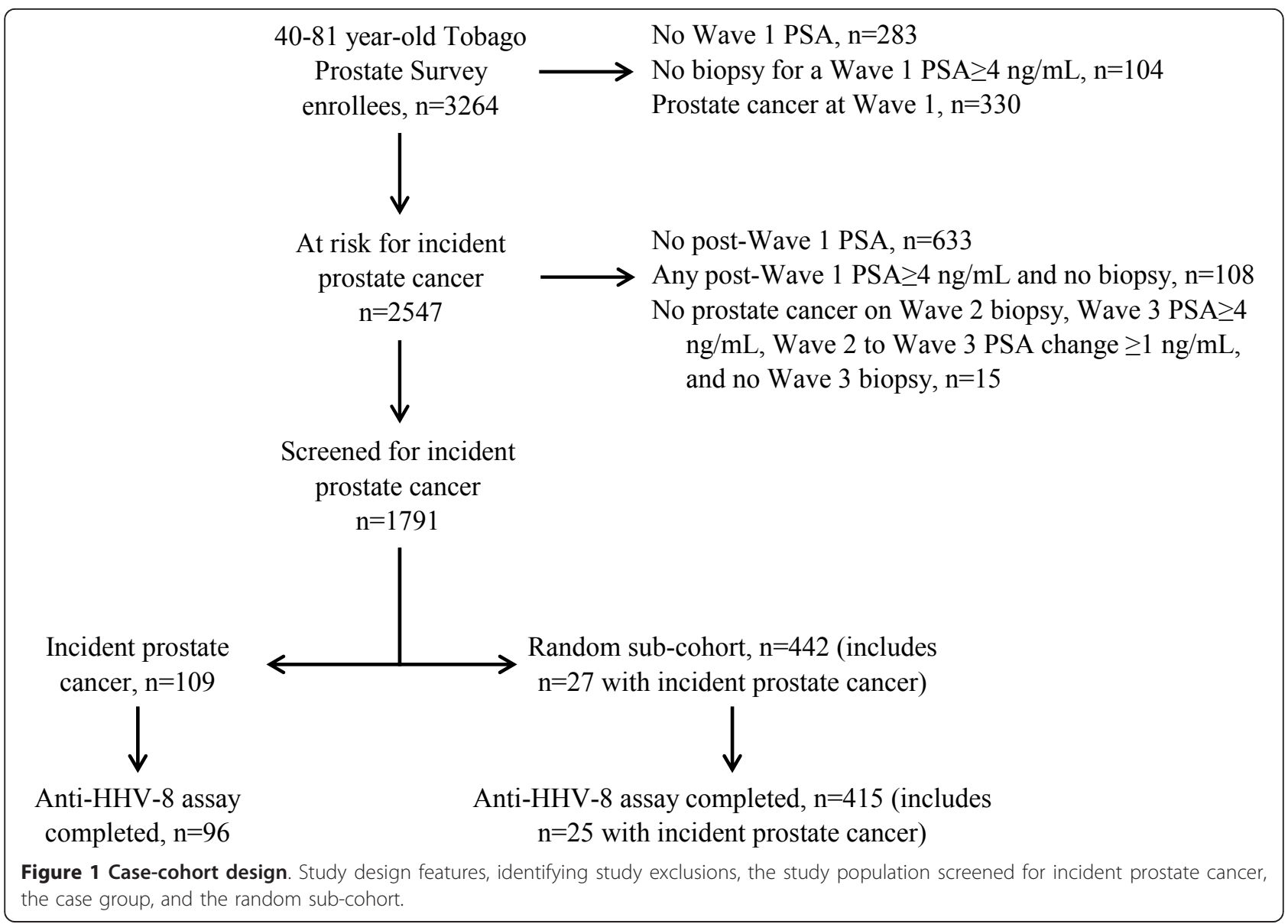

permeabilized B cells that have been induced to replicate $\mathrm{HHV}-8$, this assay potentially identifies any of the lytic proteins involved in HHV-8 replication. A single reader (FJJ), blinded to samples' prostate cancer case status, examined microscopic slides for fluorescence. A positive assay result required specific fluorescence at a 1:100 dilution. Each assay run included prostate cancer case and non-case subject sera and known HHV-8 positive and negative control sera. We tested each sample in duplicate on separate days with disagreements resolved by retesting on a third day. Estimates of assay sensitivity and specificity range between 53.4-89.9\% and 96.6$97.5 \%$, respectively [31]. Kappa agreement between first and second assay results was 0.76 (95\% CI 0.71-0.81).

\section{Data Analysis}

We used the chi-square test to evaluate 1) the statistical significance of differences between at-risk men with incomplete $v s$. complete follow-up with respect to baseline factors such as age, education, marital status, family history of prostate cancer, history of smoking, cancer, and benign prostatic hypertrophy, and results from PSA and DRE screening and 2) the statistical significance of differences in the sub-cohort rates of HHV-8 seropositivity with respect to the same baseline factors. In analyses restricted to sub-cohort members, logistic regression estimated odds ratios to express strengths of association between Wave 1 PSA elevation and Wave 1 HHV-8 seropositivity, two factors determined at the same point in time. We used Cox proportional hazards models (Breslow weighted denominator method) for case-cohort designs to estimate hazard ratio [HR] measures of unadjusted and age-adjusted association between HHV-8 seropositivity measured at baseline (Wave 1) and prostate cancer detected later in time, at Wave 2 or Wave 3 [32]. These models compare prostate cancer cases detected at one or the other points in time (Wave 2 or Wave 3) with the appropriate risk set, constructed from sub-cohort members disease-free and available at Wave 2 or Wave 3. For prostate cancer cases in the sub-cohort, Cox models started follow-up at the Wave 1 screening date and censored follow-up at the Wave 2 or Wave 3 screening date that led to prostate cancer diagnosis. For non-cases in the sub-cohort, Cox models started follow-up at the Wave 1 screening date and censored follow-up at the date of the last 
completed Wave 2 or Wave 3 screening. Calculating age on the date of the Wave 1 PSA blood collection, age adjustments used either two age categories (40-59 and $\geq$ 60 years), three age categories $(40-49,50-59$, or $\geq 60$ years), four age categories (40-44, 45-49, 50-59, and $\geq$ 60 years), or age (integer years) modeled as a continuous variable. Statistical inferences used a $\mathrm{p}=0.05$ twosided significance level.

\section{Results}

Table 1 summarizes the characteristics of all 3264 40-81 year-old men enrolled at Wave 1 . The current study excluded 717 men missing a Wave 1 PSA, men with Wave 1 PSA $\geq 4.0 \mathrm{ng} / \mathrm{mL}$ not followed by prostate biopsy, and men with prostate cancer detected at Wave 1, leaving 2547 screen-negative men at risk for prostate cancer at Wave 2 or Wave 3 (Figure 1). Table 1 compares these 2547 at-risk men with the 717 men who were either inadequately screened at Wave 1 or discovered to have prostate cancer at Wave 1. At-risk men were younger and better educated (Table 1). At-risk men less often reported a history of smoking, cancer, or benign prostatic hypertrophy (Table 1). PSA values were lower and DRE results positive less often in at-risk men, as expected, since the group not at risk included men with prostate cancer detected as direct result of PSA elevation or DRE abnormality (Table 1). The study design excluded 756 men from the group of 2547 at-risk men eligible for follow-up (Figure 1). As shown in Table 1 the 756 at-risk men with incomplete follow-up differed from the 1791 men with complete follow-up, as follows, age $(35.6 \% \mathrm{vs}$. $26.0 \% \geq 60$ years), smoking history ( $48.5 \% v s .39 .6 \%)$, personal cancer history ( $1.3 \%$ vs. $0.3 \%)$, Wave 1 PSA $\geq 4 \mathrm{ng} /$ $\mathrm{mL}(13.5 \%$ vs. $5.5 \%)$, and Wave 1 DRE (64.7\% vs. $76.3 \%$ negative and $20.0 \%$ vs. $10.3 \%$ missing).

Wave 1 HHV-8 serologic status was available for 415 (93.9\% of 442) men in the sub-cohort and for 96 (88.1\% of 109) men in the case group (Gleason 6 - 49\%, Gleason 7 - 45\%, Gleason 8 or 9 - 6\%; pre-diagnostic PSA, mean $10.0 \mathrm{ng} / \mathrm{mL}$ and median $4.4 \mathrm{ng} / \mathrm{mL}$ ). Table 2 summarizes the baseline characteristics for these men with non-missing HHV-8. In addition, Table 2 compares sub-cohort rates of HHV-8 seropositivity according to the same baseline characteristics. Referenced against the subcohort, characteristics of the case group included older age, less frequent smoking history, more frequent benign prostatic hypertrophy history, more frequently elevated Wave 1 PSA (27.1\% vs. 5.5\% PSA $\geq 4 \mathrm{ng} / \mathrm{mL})$, and more frequently positive Wave 1 prostate cancer screening (43.8\% vs. $16.9 \%$ DRE or PSA positive). Case and subcohort HHV-8 seropositivity rates were $17.7 \%$ and $11.1 \%$, respectively. When compared with 40-49 year-old subcohort men (3.5\% HHV-8 seropositive), HHV-8 seropositivity was higher in 50-59 year-old sub-cohort men
(13.6\% HHV-8 seropositive) and higher yet in $\geq 60$ yearold sub-cohort men (22.9\% HHV-8 seropositive). HHV-8 seropositivity rates were lower in sub-cohort men with a history of smoking than those without ( $7.1 \%$ vs. 13.9\%) and higher in sub-cohort men with a history of benign prostatic hypertrophy than those without $(24.0 \% v s$. 10.5\%). HHV-8 seropositivity increased with Wave 1 PSA $(7.6 \%, 12.1 \%, 12.7 \%$, and $30.4 \%$ for PSA $0.0-0.9,1.0-1.9$, 2.0-3.9, and $\geq 4 \mathrm{ng} / \mathrm{mL}$, respectively). HHV-8 seropositivity was higher in men with elevated $(\geq 4.0 \mathrm{ng} / \mathrm{mL})$ than men with non-elevated PSA (30.4\% vs. 9.9\% seropositive; crude OR 3.96, 95\% CI 1.53-10.2; age-adjusted OR 2.42, 95\% CI 0.91-6.47; data not shown). HHV-8 seropositivity was higher in sub-cohort men with a positive than in men with a negative Wave 1 prostate cancer screen result (20.0\% vs. 9.3\% seropositive).

Table 3 compares Wave 1 HHV-8 seropositivity between the case and sub-cohort groups, according to age and Wave 1 PSA. Age-specific HHV-8 seropositivity rates were lower in case than sub-cohort men (40-49 years: $0.0 \%$ vs. $3.5 \%$ and $50-59$ years: $10.8 \%$ vs. $13.6 \%$ ), except in the oldest age group ( $\geq 60$ years: $27.7 \% v s$. $22.9 \%)$. In men with a non-elevated $(<4 \mathrm{ng} / \mathrm{mL})$ Wave 1 PSA, the HHV-8 seropositivity rate was higher in the case group $(17.1 \%$ vs. $9.9 \%)$. In men with an elevated ( $\geq$ $4 \mathrm{ng} / \mathrm{mL}$ ) Wave 1 PSA, however, the HHV-8 seropositivity rate was lower in the case group (19.2\% vs. $30.4 \%)$. In the two age sub-groups with appreciable HHV-8 seropositivity, age-specific HHV-8 seropositivity rates were not consistently higher or lower in case than sub-cohort men with non-elevated Wave 1 PSA (50-59 years: $11.5 \%$ vs. $13.7 \%$ and $\geq 60$ years: $28.1 \%$ vs. $20.4 \%$ ) and consistently lower in case than sub-cohort men with elevated Wave 1 PSA (50-59 years: $9.1 \%$ vs. $12.5 \%$ and $\geq 60$ years: $26.7 \%$ vs. $41.7 \%$ ).

Table 4 shows associations, unadjusted and ageadjusted, between Wave $1 \mathrm{HHV}-8$ seropositivity and prostate cancer at Wave 2 or Wave 3, overall and in sub-groups defined by Wave 1 screen results. Though not statistically significant, HR point estimates indicate lower prostate cancer risk in HHV-8 seropositive men, overall (age-adjusted HR 0.88, 95\% CI 0.46-1.69) and in HHV-8 seropositive men with elevated Wave 1 PSA (age-adjusted HR 0.39, 95\% CI 0.10-1.63), and equivalent risk in HHV-8 seropositive men with non-elevated Wave 1 PSA (age-adjusted HR 1.03, 95\% CI 0.49-2.16). In men eligible for prostate biopsy at Wave 1 (DRE or PSA positive), HHV-8 seropositivity reduced risk (ageadjusted HR $0.59,95 \%$ CI $0.18-1.91$ ) to a statistically insignificant level. In perhaps the most meaningful subgroup, men not eligible for prostate biopsy at Wave 1 (DRE not positive and PSA $<4.0 \mathrm{ng} / \mathrm{mL}$ ), analyses supplied no evidence of association between seropositivity and prostate cancer risk (age-adjusted HR: 1.02, 95\% CI 
Table 1 Characteristics of all men enrolled at Wave 1, men not at risk and at risk for prostate cancer at Wave 2 or Wave 3 based on Wave 1 screen results, and at-risk men with incomplete and complete follow-up.

\begin{tabular}{|c|c|c|c|c|c|c|c|c|c|c|c|}
\hline \multirow[b]{3}{*}{ Characteristic } & & & \multicolumn{4}{|c|}{ Risk status after Wave 1} & \multicolumn{4}{|c|}{ Follow-up } & \multirow[b]{3}{*}{ p-value ${ }^{2}$} \\
\hline & \multicolumn{2}{|c|}{$\begin{array}{c}\text { All } \\
n=3264\end{array}$} & \multicolumn{2}{|c|}{$\begin{array}{c}\text { Not at risk } \\
n=717\end{array}$} & \multicolumn{2}{|c|}{$\begin{array}{c}\text { At risk } \\
n=2547\end{array}$} & \multicolumn{2}{|c|}{$\begin{array}{c}\text { Incomplete } \\
\mathrm{n}=756\end{array}$} & \multicolumn{2}{|c|}{$\begin{array}{l}\text { Complete } \\
n=1791\end{array}$} & \\
\hline & $n^{1}$ & $\%$ & $n^{1}$ & $\%$ & $n^{1}$ & $\%$ & $n^{1}$ & $\%$ & $\mathrm{n}^{1}$ & $\%$ & \\
\hline \multicolumn{12}{|l|}{ Demographic } \\
\hline Age (years) & & & & & & & & & & & $<.0001$ \\
\hline $40-44$ & 624 & 19.1 & 59 & 8.2 & 565 & 22.2 & 151 & 20.0 & 414 & 23.1 & \\
\hline $45-49$ & 571 & 17.5 & 71 & 9.9 & 500 & 19.6 & 115 & 15.2 & 385 & 21.5 & \\
\hline $50-59$ & 914 & 28.0 & 166 & 23.2 & 748 & 29.4 & 221 & 29.2 & 527 & 29.4 & \\
\hline $60-81$ & 1155 & 35.4 & 421 & 58.7 & 734 & 28.8 & 269 & 35.6 & 465 & 26.0 & \\
\hline Education & $(23)$ & & (7) & & (16) & & (7) & & (9) & & 0.76 \\
\hline$\leq 11$ years & 2411 & 74.4 & 553 & 77.9 & 1858 & 73.4 & 553 & 73.8 & 1305 & 73.2 & \\
\hline $12+$ years & 830 & 25.6 & 157 & 22.1 & 673 & 26.6 & 196 & 26.2 & 477 & 26.8 & \\
\hline Marital status & (26) & & (10) & & $(16)$ & & (7) & & (9) & & 0.13 \\
\hline ever married & 2669 & 82.4 & 590 & 83.5 & 2079 & 82.1 & 602 & 80.4 & 1477 & 82.9 & \\
\hline never married & 569 & 17.6 & 117 & 16.5 & 452 & 17.9 & 147 & 19.6 & 305 & 17.1 & \\
\hline \multicolumn{12}{|l|}{ Family history of ... } \\
\hline Prostate cancer & & & & & & & & & & & 0.02 \\
\hline missing & 323 & 9.9 & 77 & 10.7 & 246 & 9.7 & 86 & 11.4 & 160 & 8.9 & \\
\hline yes & 218 & 6.7 & 40 & 5.6 & 178 & 7.0 & 64 & 8.5 & 114 & 6.4 & \\
\hline no & 2723 & 83.4 & 600 & 83.7 & 2123 & 83.4 & 606 & 80.2 & 1517 & 84.7 & \\
\hline \multicolumn{12}{|l|}{ History of ... } \\
\hline Smoking & $(21)$ & & (7) & & (14) & & (3) & & (11) & & $<.0001$ \\
\hline yes & 1410 & 43.5 & 341 & 48.0 & 1069 & 42.2 & 365 & 48.5 & 704 & 39.6 & \\
\hline no & 1833 & 56.5 & 369 & 52.0 & 1464 & 57.8 & 388 & 51.5 & 1076 & 60.4 & \\
\hline Cancer & $(43)$ & & (13) & & (30) & & (9) & & (21) & & 0.002 \\
\hline yes & 26 & 0.8 & 11 & 1.6 & 15 & 0.6 & 10 & 1.3 & 5 & 0.3 & \\
\hline no & 3195 & 99.2 & 693 & 98.4 & 2502 & 99.4 & 737 & 98.7 & 1765 & 99.7 & \\
\hline Benign prostatic hypertrophy & (84) & & (24) & & $(60)$ & & (17) & & (43) & & 0.67 \\
\hline yes & 248 & 7.8 & 78 & 11.3 & 170 & 6.8 & 53 & 7.2 & 117 & 6.7 & \\
\hline no & 2932 & 92.2 & 615 & 88.7 & 2317 & 93.2 & 686 & 92.8 & 1631 & 93.3 & \\
\hline \multicolumn{12}{|l|}{ Entry prostate cancer screen } \\
\hline $\mathrm{PSA}(\mathrm{ng} / \mathrm{mL})$ & $(190)$ & & $(190)$ & & & & & & & & $<.0001$ \\
\hline $0.0-0.9$ & 1213 & 39.5 & 43 & 8.2 & 1170 & 45.9 & 306 & 40.5 & 864 & 48.2 & \\
\hline $1.0-1.9$ & 850 & 27.7 & 45 & 8.5 & 805 & 31.6 & 206 & 27.2 & 599 & 33.4 & \\
\hline $2.0-2.9$ & 268 & 8.7 & 21 & 4.0 & 247 & 9.7 & 84 & 11.1 & 163 & 9.1 & \\
\hline $3.0-3.9$ & 150 & 4.9 & 26 & 4.9 & 124 & 4.9 & 58 & 7.7 & 66 & 3.7 & \\
\hline $4.0-9.9$ & 354 & 11.5 & 199 & 37.8 & 155 & 6.1 & 73 & 9.7 & 82 & 4.6 & \\
\hline $10+$ & 239 & 7.8 & 193 & 36.6 & 46 & 1.8 & 29 & 3.8 & 17 & 0.9 & \\
\hline DRE & & & & & & & & & & & $<.0001$ \\
\hline missing & 555 & 17.0 & 220 & 30.7 & 335 & 13.2 & 151 & 20.0 & 184 & 10.3 & \\
\hline positive & 636 & 19.5 & 279 & 38.9 & 357 & 14.0 & 116 & 15.3 & 241 & 13.5 & \\
\hline negative & 2073 & 63.5 & 218 & 30.4 & 1855 & 72.8 & 489 & 64.7 & 1366 & 76.3 & \\
\hline
\end{tabular}

PSA - prostate-specific antigen, DRE - digital rectal examination

1. Numbers in parentheses indicate missing data

2. Statistical significance (chi-square) of differences between at-risk men with incomplete and complete follow-up

0.44-2.39). In men with non-elevated Wave 1 PSA, single-year-of-age-adjusted (continuous) risk estimates were HR 0.80 (95\% CI 0.19-3.34) and HR 1.27 (95\% CI $0.50-3.25)$ for the $50-59$ and $\geq 60$ year-old men, respectively (data not shown). Using all (96 case and 415 sub-cohort) men or only $\geq 45$ year-old (95 case and 312 sub-cohort) men made no meaningful difference in the age-adjusted risk estimates (data not shown). 
Table 2 Case and sub-cohort group characteristics, with sub-cohort rate of HHV-8 seropositivity, according to baseline characteristic

\begin{tabular}{|c|c|c|c|c|c|c|c|}
\hline \multirow[b]{2}{*}{ Characteristic } & \multicolumn{2}{|c|}{ Cases $(n=96)$} & \multicolumn{2}{|c|}{ Sub-cohort $(n=415)$} & \multicolumn{2}{|c|}{ Sub-cohort HHV-8 Pos } & \multirow[b]{2}{*}{$\mathrm{p}$-value ${ }^{2}$} \\
\hline & $n^{1}$ & Col \% & $n^{1}$ & Col \% & $\mathrm{n}^{1}$ & Row \% & \\
\hline Demographic & & & & & & & $<.0001$ \\
\hline \multicolumn{8}{|l|}{ Age (years) } \\
\hline $40-49$ & 12 & 12.5 & 200 & 48.2 & 7 & 3.5 & \\
\hline $50-59$ & 37 & 38.5 & 110 & 26.5 & 15 & 13.6 & \\
\hline $60-81$ & 47 & 49.0 & 105 & 25.3 & 24 & 22.9 & \\
\hline Education & & & (2) & & (0) & & 0.83 \\
\hline$\leq 11$ years & 77 & 80.2 & 318 & 77.0 & 36 & 11.3 & \\
\hline $12+$ years & 19 & 19.8 & 95 & 23.0 & 10 & 10.5 & \\
\hline Marital status & & & & & & & 0.48 \\
\hline ever married & 82 & 85.4 & 336 & 81.0 & 39 & 11.6 & \\
\hline never married & 14 & 14.6 & 79 & 19.0 & 7 & 8.9 & \\
\hline \multicolumn{8}{|l|}{ Family history of ... } \\
\hline Prostate cancer & & & & & & & 0.80 \\
\hline missing & 5 & 5.2 & 32 & 7.7 & 4 & 12.5 & \\
\hline yes & 5 & 5.2 & 27 & 6.5 & 2 & 7.4 & \\
\hline no & 86 & 89.6 & 356 & 85.8 & 40 & 11.2 & \\
\hline \multicolumn{8}{|l|}{ History of ... } \\
\hline Smoking & & & (1) & & (0) & & 0.029 \\
\hline yes & 34 & 35.4 & 170 & 41.1 & 12 & 7.1 & \\
\hline no & 62 & 64.6 & 244 & 58.9 & 34 & 13.9 & \\
\hline Benign prostatic hypertrophy & (3) & & (8) & & (0) & & 0.039 \\
\hline yes & 10 & 10.8 & 25 & 6.1 & 6 & 24.0 & \\
\hline no & 83 & 89.2 & 382 & 93.9 & 40 & 10.5 & \\
\hline \multicolumn{8}{|l|}{ Entry prostate cancer screen } \\
\hline PSA (ng/mL) & & & & & & & 0.010 \\
\hline $0.0-0.9$ & 7 & 7.3 & 197 & 47.5 & 15 & 7.6 & \\
\hline $1.0-1.9$ & 27 & 28.1 & 140 & 33.7 & 17 & 12.1 & \\
\hline $2.0-3.9$ & 36 & 37.5 & 55 & 13.3 & 7 & 12.7 & \\
\hline$\geq 4.0$ & 26 & 27.1 & 23 & 5.5 & 7 & 30.4 & \\
\hline DRE & & & & & & & 0.34 \\
\hline missing & 4 & 4.2 & 48 & 11.6 & 4 & 8.3 & \\
\hline positive & 29 & 30.2 & 54 & 13.0 & 9 & 16.7 & \\
\hline negative & 63 & 65.6 & 313 & 75.4 & 33 & 10.5 & \\
\hline DRE positive and/or PSA $\geq 4 \mathrm{ng} / \mathrm{mL}$ & & & & & & & 0.009 \\
\hline yes & 42 & 43.8 & 70 & 16.9 & 14 & 20.0 & \\
\hline no & 54 & 56.3 & 345 & 83.1 & 32 & 9.3 & \\
\hline \multicolumn{8}{|l|}{ Study-specific } \\
\hline \multicolumn{8}{|l|}{ HHV-8 sero-status } \\
\hline positive & 17 & 17.7 & 46 & 11.1 & & & \\
\hline negative & 79 & 82.3 & 369 & 88.9 & & & \\
\hline
\end{tabular}

PSA - prostate-specific antigen, DRE - digital rectal examination, HHV-8 - human herpesvirus 8

1. Numbers in parentheses indicate missing data

2. Statistical significance (chi-square) of differences in HHV-8 seropositivity according to baseline characteristic

\section{Discussion}

Our previous study used an immunofluorescence assay to measure HHV-8 antibodies in 138 prostate cancer cases and in 140 age-matched controls [9]. HHV-8 seropositivity was significantly more frequent in cases than controls (39.9\% vs. $22.9 \%$, OR $2.24,95 \%$ CI $1.29-3.90)$ [9]. Our previous study compared Wave 1 screendetected (DRE positive and/or PSA elevated) prostate cancer cases with DRE negative and PSA non-elevated controls. In the same Tobago study population, using a 
Table 3 Sub-cohort and case group Wave 1 HHV-8 seropositivity, by age and Wave 1 PSA result

\begin{tabular}{|c|c|c|c|c|c|c|c|}
\hline \multirow{3}{*}{ Age years } & \multirow{3}{*}{ PSA $n g / m L$} & \multirow{2}{*}{\multicolumn{3}{|c|}{$\begin{array}{c}\text { Cases } \\
\text { HHV-8 positive }\end{array}$}} & \multirow{2}{*}{\multicolumn{3}{|c|}{$\begin{array}{l}\text { Sub-cohort } \\
\text { HHV-8 positive }\end{array}$}} \\
\hline & & & & & & & \\
\hline & & $n$ & $n$ & $\%$ & $\mathrm{n}$ & $n$ & $\overline{\%}$ \\
\hline $40-49$ & All & 12 & 0 & 0.0 & 200 & 7 & 3.5 \\
\hline 50-59 & All & 37 & 4 & 10.8 & 110 & 15 & 13.6 \\
\hline$\geq 60$ & All & 47 & 13 & 27.7 & 105 & 24 & 22.9 \\
\hline All & $<4$ & 70 & 12 & 17.1 & 392 & 39 & 9.9 \\
\hline All & $\geq 4$ & 26 & 5 & 19.2 & 23 & 7 & 30.4 \\
\hline $40-49$ & $<4$ & 12 & 0 & 0.0 & 197 & 6 & 3.0 \\
\hline $50-59$ & $<4$ & 26 & 3 & 11.5 & 102 & 14 & 13.7 \\
\hline$\geq 60$ & $<4$ & 32 & 9 & 28.1 & 93 & 19 & 20.4 \\
\hline $40-49$ & $\geq 4$ & & & & 3 & 1 & 33.3 \\
\hline $50-59$ & $\geq 4$ & 11 & 1 & 9.1 & 8 & 1 & 12.5 \\
\hline$\geq 60$ & $\geq 4$ & 15 & 4 & 26.7 & 12 & 5 & 41.7 \\
\hline
\end{tabular}

PSA - prostate-specific antigen, DRE - digital rectal examination, HHV-8 human herpesvirus 8

similar assay, the current prospective case-cohort study offered an opportunity to evaluate temporal relationships between HHV-8 seropositivity and prostate cancer, in men with and without elevated PSA at baseline. Including men with non-elevated $(<4.0 \mathrm{ng} / \mathrm{mL})$ Wave 1 PSA and men with elevated $(\geq 4.0 \mathrm{ng} / \mathrm{mL})$ Wave 1 PSA, but prostate cancer not seen on Wave 1 biopsy, casecohort analysis did not observe HHV-8-related incident prostate cancer risk in men overall (age-adjusted HR 0.88, 95\% CI 0.46-1.69), in men with Wave 1 PSA < 4 $\mathrm{ng} / \mathrm{mL}$ (age-adjusted HR 1.03, 95\% CI 0.49-2.16), or in men without a positive Wave 1 prostate cancer screen result (age-adjusted HR 1.02, 95\% CI 0.44-2.39; Table 4).

A positive association between HHV-8 seropositivity and prevalent prostate cancer in a cross-sectional study [9] and an inverse (though not statistically significant) association in a prospective study, an inverse association most evident in men sent for biopsy (e.g., PSA $\geq 4 \mathrm{ng} /$
mL, age-adjusted HR 0.39, 95\% CI 0.10-1.63; Table 4), lead to the following speculation. HHV-8 may associate with factors, such as elevated PSA, that prompt biopsy and subsequent recognition of prostate cancer. In effect, HHV-8 may segregate men with manifest and emergent prostate cancer into two groups, HHV-8 seropositive prostate cancer detected immediately and HHV-8 seronegative prostate cancer detected later. This selection bias may explain opposing positive and negative HHV-8 associations seen with prevalent and incident prostate cancer, respectively. A similar selection bias may explain inverse associations between HHV-8 and prostate cancer observed in other prospective studies, as described below.

Four comparative studies of HHV-8 and prostate cancer have appeared $[6,11,26,27]$ since our 2004 publication [9]. In a prospective study from Finland, ELISA detected serum antibodies against the HHV-8 ORF65 protein in 3 (1.8\%) of 163 men with incident prostate cancer and in 7 (2.4\%) of 288 age-matched men without cancer (OR 0.74, 95\% CI 0.19-2.88; [27]). In a U.S. population-based casecontrol study, the immunofluorescence assay detected serum antibodies against HHV-8 lytic antigens less often in cases than controls (95 African-American cases and 75 controls: OR $0.56,95 \%$ CI $0.28-1.14 ; 104$ white cases and 80 controls: OR $0.71,95 \%$ CI $0.36-1.43$; [26]). In a study of 691 individually matched case-control pairs nested within the U.S. Health Professional Follow-up Study, the immunofluorescence assay detected plasma antibodies against lytic antigens less often in men diagnosed with prostate cancer, on average, 3.1 years later (OR 0.70, 95\% CI 0.520.95; [6]). Finally, in the Prostate, Lung, Colorectal, and Ovarian (PLCO) Cancer Screening Trial, ELISA detected IgG antibodies against the HHV-8 K8.1 structural protein in study entry serum samples from 103 (13.5\%) of 765 and $103(11.3 \%)$ of 915 white prostate cancer cases and agematched controls, respectively (OR 1.3, 95\% CI 0.9-1.7)

Table 4 Unadjusted and age-adjusted associations (hazard ratio) between Wave 1 HHV-8 seropositivity and prostate cancer at Wave 2 or Wave 3, overall and within strata defined by Wave 1 prostate cancer screening test results

\begin{tabular}{|c|c|c|c|c|c|c|c|c|}
\hline \multirow[t]{2}{*}{ Wave 1 prostate cancer screening test result } & \multicolumn{2}{|c|}{ Cases } & \multicolumn{2}{|c|}{ Sub-cohort } & \multicolumn{2}{|c|}{ Unadjusted } & \multicolumn{2}{|c|}{ Age-adjusted } \\
\hline & Pos & $\mathrm{n}$ & Pos & $\mathrm{n}$ & $\mathrm{HR}$ & $95 \% \mathrm{Cl}$ & HR & $95 \% \mathrm{Cl}$ \\
\hline Overall & 17 & 96 & 46 & 415 & 1.46 & $0.78-2.74$ & $0.88^{1}$ & $0.46-1.69$ \\
\hline \multicolumn{9}{|l|}{ PSA (ng/mL) } \\
\hline$<4$ & 12 & 70 & 39 & 392 & 1.61 & $0.77-3.38$ & $1.03^{1}$ & $0.49-2.16$ \\
\hline$\geq 4$ & 5 & 26 & 7 & 23 & 0.44 & $0.11-1.71$ & $0.39^{2}$ & $0.10-1.63$ \\
\hline \multicolumn{9}{|l|}{ DRE positive or PSA $\geq 4 \mathrm{ng} / \mathrm{mL}$} \\
\hline no & 9 & 54 & 32 & 345 & 1.67 & $0.72-3.86$ & $1.02^{1}$ & $0.44-2.39$ \\
\hline yes & 8 & 42 & 14 & 70 & 0.85 & $0.52-2.38$ & $0.59^{3}$ & $0.18-1.91$ \\
\hline
\end{tabular}

Pos - number HHV-8 positive, $\mathrm{n}$ - case or sub-cohort count, HR - hazard ratio, $\mathrm{Cl}$ - confidence interval, PSA - prostate-specific antigen, DRE - digital rectal examination

1. Adjusted across four age categories: $40-44,45-49,50-59, \geq 60$ years

2. Adjusted across two age categories: $40-59, \geq 60$ years

3. Adjusted across three age categories: $40-49,50-59, \geq 60$ years 
and in $2(1.9 \%)$ of 103 and $22(6.0 \%)$ of 367 black cases and age-matched controls, respectively (OR 0.3, 95\% CI $0.1-1.4 ;[11])$. On balance, these studies suggest that HHV8 does not influence prostate cancer risk.

Analyses restricted to the sub-cohort showed strong association 1) between $\mathrm{HHV}-8$ seropositivity and increasing age, a result also seen in Tobago women [33] and many other populations [34,35], and 2) between HHV-8 seropositivity and PSA elevation $\geq 4.0 \mathrm{ng} / \mathrm{mL}$. Though not statistically significant $(\mathrm{p}=0.17)$, ageadjusted geometric mean Wave 1 PSA was $18 \%$ higher in HHV-8 seropositive than seronegative sub-cohort men (data not shown). The age-adjusted odds of HHV-8 seropositivity was more than two-fold higher in subcohort men with elevated PSA than men with non-elevated PSA. Personal or environmental factors related to HHV-8 exposure or immune function may explain the age association with HHV-8 [33]. Accepting PSA as a marker of prostate inflammation, we postulate that the association between HHV-8 seropositivity and elevated PSA signifies either the effects of $\mathrm{HHV}-8$ infection on prostate inflammation [19] or the effects of prostate inflammation on HHV-8 reactivation. PSA elevation has been observed in relation to other infectious disease agents [36,37].

Study strengths include unique population and setting (predominantly African ancestry Tobago residents [38]) and a control group large enough to estimate age-specific HHV-8 seroprevalence rates with acceptable precision. Study limitations include unavoidable misclassification according to prostate cancer outcome. DRE and PSA invariably miss instances of biopsy detectable prostate cancer. The Prostate Cancer Prevention Trial, for example, observed a $15 \%$ prostate cancer biopsy prevalence in men with PSA $\leq 4 \mathrm{ng} / \mathrm{mL}$ [39]. In addition, our study can not define the prostate cancer risk experience of men who did not return for repeat screening. Follow-up intervals much longer than our five-year interval between initial and final screening may be needed to detect a prostate cancer effect from any chronic inflammation caused by HHV-8 infection. Also, HHV-8 may cause inflammation and prostate cancer only in a relatively small genetically susceptible subgroup. Finally, a small case count limits, especially in subgroups, the precision of our risk estimates. For example, in men not eligible for prostate biopsy at Wave 1, the $95 \%$ confidence interval embraced both 50\% lower and 200\% higher prostate cancer risks in relation to $\mathrm{HHV}-8$ seropositivity.

\section{Conclusions}

Our prospective study could not demonstrate an association between HHV-8 seropositivity and incident prostate cancer. However, analyses uncovered a strong relationship between elevated $\mathrm{HHV}-8$ seropositivity and
PSA. The HHV-8 association previously observed with prevalent prostate cancer may signify enhanced detection of prostate cancer possibly caused by the effects of HHV-8 on PSA. In this context, the association we observed between HHV-8 seropositivity and PSA elevation deserves further study.

List of Abbreviations

HHV-8: human herpesvirus 8; DRE: digital rectal examination; PSA: prostatespecific antigen; OR: odds ratio; Cl: confidence interval; HR: hazards ratio; HPV: human papillomavirus; PLCO: Prostate Lung Colorectal, and Ovarian Cancer Screening Trial.

\section{Acknowledgements}

The study was supported, in part, by funding or in-kind services received from the Tobago House of Assembly, the University of Pittsburgh Cancer Institute, the University of Pittsburgh, the U.S. Department of Defense (DAMD 17-99-1-9015), and the National Institutes of Health (R01 CA84950 R25 CA057703 and R25 CA094061). The authors thank Dr. Emanuela Taioli for her support and guidance.

\section{Author details}

'Department of Epidemiology, Columbia University, 722 West 168th Street, 729, New York, New York, 10032, USA. ²Department of Pathology, University of Pittsburgh, HCCLB Room G.17, 5117 Centre Avenue, Pittsburgh, Pennsylvania, 15232, USA. ${ }^{3}$ Department of Epidemiology, University of Pittsburgh, A542 Crabtree Hall, 130 DeSoto Street, Pittsburgh, Pennsylvania, 15261, USA. ${ }^{4}$ University of Pittsburgh Cancer Institute, UPMC Cancer Pavilion, Suite 4-C, 5150 Centre Avenue, Pittsburgh, Pennsylvania, 15232, USA. ${ }^{5}$ Department of Biostatistics, University of Pittsburgh, 310 Parran Hall, 130 DeSoto Street, Pittsburgh, Pennsylvania, 15261, USA. ${ }^{6}$ Tobago Health Studies Office, Scarborough, Tobago, Trinidad and Tobago.

\section{Authors' contributions}

ACM participated in study design, data analysis and interpretation, prepared a first draft of the manuscript, and helped revise the final manuscript. FJJ completed immunofluorescence assays and helped revise the final manuscript. CHB conceived the study, acquired data, provided study coordination, and helped revise the final manuscript. JWW selected analytic methods and directed statistical analysis. ALP acquired data and provided study coordination. JLW participated in study design, data analysis and interpretation and helped revise the final manuscript. All authors read and approved the final manuscript.

\section{Competing interests}

The authors declare that they have no competing interests.

Received: 10 August 2011 Accepted: 7 December 2011 Published: 7 December 2011

\section{References}

1. Ferlay J, Shin H-R, Bray F, Forman D, Mathers C, Parkin DM: Estimates of worldwide burden of cancer in 2008: GLOBOCAN 2008. International Journal of Cancer 2010.

2. Bunker CH, Patrick AL, Miljkovic-Gacic I, Konety BR, Belle A, Richard JR, Dhir R: Prostate cancer screening parameters in a high-risk AfricanCaribbean population. Urology 2004, 63:737-741

3. Chinegwundoh F, Enver M, Lee A, Nargund V, Oliver T, Ben-Shlomo Y: Risk and presenting features of prostate cancer amongst African-Caribbean, South Asian and European men in North-east London. BJU International 2006, 98:1216-1220.

4. Glover FE Jr, Coffey DS, Douglas LL, Cadogan M, Russell H, Tulloch T, Baker TD, Wan RL, Walsh PC: The epidemiology of prostate cancer in Jamaica. Journal of Urology 1998, 159:1984-1986; discussion 1986-1987.

5. Sawczuk IC, Shabisgh A: Cancer of the prostate: Incidence in the USA. In Prostate Cancer Science and Clinical Practice. Edited by: Mydlo JH, Godec CJ. London: Academic Press; 2003: 
6. Sutcliffe S, Giovannucci E, Gaydos CA, Viscidi RP, Jenkins FJ, Zenilman JM, Jacobson LP, De Marzo AM, Willett WC, Platz EA: Plasma antibodies against Chlamydia trachomatis, human papillomavirus, and human herpesvirus type 8 in relation to prostate cancer: a prospective study. Cancer Epidemiology, Biomarkers \& Prevention 2007, 16:1573-1580.

7. Dennis LK, Lynch CF, Torner JC: Epidemiologic association between prostatitis and prostate cancer. Urology 2002, 60:78-83.

8. Dillner J, Knekt P, Boman J, Lehtinen M, Af Geijersstam V, Sapp M, Schiller J, Maatela J, Aromaa A: Sero-epidemiological association between humanpapillomavirus infection and risk of prostate cancer. International Journal of Cancer 1998, 75:564-567.

9. Hoffman LJ, Bunker CH, Pellett PE, Trump DL, Patrick AL, Dollard SC, Keenan HA, Jenkins FJ: Elevated seroprevalence of human herpesvirus 8 among men with prostate cancer. Journal of Infectious Diseases 2004 189:15-20.

10. Palapattu GS, Sutcliffe S, Bastian PJ, Platz EA, De Marzo AM, Isaacs WB, Nelson WG: Prostate carcinogenesis and inflammation: emerging insights. Carcinogenesis 2005, 26:1170-1181.

11. Huang W-Y, Hayes R, Pfeiffer R, Viscidi RP, Lee FK, Wang YF, Reding D, Whitby D, Papp JR, Rabkin CS: Sexually transmissible infections and prostate cancer risk. Cancer Epidemiology, Biomarkers \& Prevention 2008, 17:2374-2381

12. Capuano M, La Parola IL, Cattani P, Cerimele F, Sasso F, Masini C, Fadda G, Cerimele D: Re: Kaposi's sarcoma associated herpesvirus deoxyribonucleic acid sequences: lack of detection in prostatic tissue of human immunodeficiency virus-negative immunocompetent adults. Journal of Urology 1998, 160:505-506.

13. De Marzo AM, Platz EA, Sutcliffe S, Xu J, Gronberg H, Drake CG, Nakai Y, Isaacs WB, Nelson WG: Inflammation in prostate carcinogenesis. Nature Reviews Cancer 2007, 7:256-269.

14. Diamond C, Brodie SJ, Krieger JN, Huang ML, Koelle DM, Diem K, Muthui D, Corey L: Human herpesvirus 8 in the prostate glands of men with Kaposi's sarcoma. Journal of Virology 1998, 72:6223-6227.

15. Monini P, de Lellis L, Fabris M, Rigolin F, Cassai E: Kaposi's sarcomaassociated herpesvirus DNA sequences in prostate tissue and human semen. New England Journal of Medicine 1996, 334:1168-1172.

16. Samanta M, Harkins L, Klemm K, Britt WJ, Cobbs CS: High prevalence of human cytomegalovirus in prostatic intraepithelial neoplasia and prostatic carcinoma. Journal of Urology 2003, 170:998-1002.

17. Strickler HD, Goedert JJ: Sexual behavior and evidence for an infectious cause of prostate cancer. Epidemiologic Reviews 2001, 23:144-151.

18. Zambrano A, Kalantari M, Simoneau A, Jensen JL, Villarreal LP: Detection of human polyomaviruses and papillomaviruses in prostatic tissue reveals the prostate as a habitat for multiple viral infections. Prostate 2002, 53:263-276.

19. Montgomery J, Jacobson L, Dhir R, Jenkins F: Detection of human Herpesvirus 8 (HHV-8) in normal prostates. Prostate 2006, 66:1302-1310.

20. Urisman A, Molinaro RJ, Fischer N, Plummer SJ, Casey G, Klein EA, Malathi K, Magi-Galluzzi C, Tubbs RR, Ganem D, et al: Identification of a novel Gammaretrovirus in prostate tumors of patients homozygous for R462Q RNASEL variant. PLoS Pathogens 2006, 2:e25.

21. Schlaberg R, Choe D, Brown K, Thaker H, Singh I: XMRV is present in malignant prostatic epithelium and is associated with prostate cancer, especially high-grade tumors. PNAS 2009, 106:16351-16356.

22. Coussens LM, Werb Z: Inflammation and cancer. Nature 2002, 420:860-867.

23. Platz EA, De Marzo AM: Epidemiology of inflammation and prostate cancer. Journal of Urology 2004, 171:S36-40.

24. Bunker CH, Patrick AL, Konety BR, Dhir R, Brufsky AM, Vivas CA, Becich MJ, Trump DL, Kuller LH: High prevalence of screening-detected prostate cancer among Afro-Caribbeans: the Tobago Prostate Cancer Survey. Cancer Epidemiology, Biomarkers \& Prevention 2002, 11:726-729.

25. Patrick A: Prostate-cancer screening in an Afro-Caribbean population: the Tobago Prostate Cancer Screening Study. BJU International 2010, 105:745-746

26. Jenkins FJ, Hayes RB, Jackson A, Pizza G, Mbisa G, Whitby D, Goedert JJ: Human herpesvirus 8 seroprevalence among prostate cancer case patients and control subjects. Journal of Infectious Diseases 2007, 196:208-211.

27. Korodi Z, Wang $X$, Tedeschi R, Knekt P, Dillner J: No serological evidence of association between prostate cancer and infection with herpes simplex virus type 2 or human herpesvirus type 8 : a nested case-control study. Journal of Infectious Diseases 2005, 191:2008-2011.

28. CARICOM Capacity Development Programme: National Census Report: Trinidad and Tobago. Greater Georgetown, Guyana: The CARICOM Secretariat; 2009 .

29. Jenkins FJ, Hoffman LJ, Liegey-Dougall A: Reactivation of and primary infection with human herpesvirus 8 among solid-organ transplant recipients. Journal of Infectious Diseases 2002, 185:1238-1243.

30. Nakamura H, Lu M, Gwack Y, Souvlis J, Zeichner SL, Jung JU: Global changes in Kaposi's sarcoma-associated virus gene expression patterns following expression of a tetracycline-inducible Rta transactivator. Journal of Virology 2003, 77:4205-4220

31. Pellett PE, Wright DJ, Engels EA, Ablashi DV, Dollard SC, Forghani B, Glynn SA, Goedert JJ, Jenkins FJ, Lee TH, et al: Multicenter comparison of serologic assays and estimation of human herpesvirus 8 seroprevalence among US blood donors. Transfusion 2003, 43:1260-1268.

32. Barlow WE, Ichikawa L, Rosner D, Izumi S: Analysis of case-cohort designs. Journal of Clinical Epidemiology 1999, 52:1165-1172

33. McDonald AC, Ragin CC, Jenkins FJ, Weissfeld J, Wilson J, Wheeler WW Wilson JB, Bunker $\mathrm{CH}$, Taioli E: Human herpesvirus 8 seroprevalence among Tobago women and the role of sexual lifestyle behavior. Journal of Medical Virology 2009, 81:264-270.

34. Cattani P, Cerimele F, Porta D, Graffeo R, Ranno S, Marchetti S, Ricci R, Capodicasa N, Fuga L, Amico R, et al: Age-specific seroprevalence of Human Herpesvirus 8 in Mediterranean regions. Clinical Microbiology \& Infection 2003, 9:274-279.

35. Cunha AMG, Caterino-de-Araujo A, Costa SCB, Santos-Fortuna E, BoaSorte NCA, Goncalves MS, Costa FF, Galvao-Castro B: Increasing seroprevalence of human herpesvirus 8 (HHV-8) with age confirms HHV8 endemicity in Amazon Amerindians from Brazil. Journal of General Virology 2005, 86:2433-2437

36. Sutcliffe S, Zenilman JM, Ghanem KG, Jadack RA, Sokoll LJ, Elliott DJ, Nelson WG, De Marzo AM, Cole SR, Isaacs WB, Platz EA: Sexually transmitted infections and prostatic inflammation/cell damage as measured by serum prostate specific antigen concentration. Journal of Urology 2006, 175:1937-1942.

37. Oliver J, Oliver R, Ballard R: Influence of circumcision and sexual behaviour on PSA levels in patients attending a sexually transmitted disease (STD) clinic. Prostate Cancer Prostatic Dis 2001, 4:228-231.

38. Miljkovic-Gacic I, Ferrell R, Patrick A, Kammerer C, Bunker C: Estimates of African, European and Native American ancestry in Afro-Caribbean men on the island of Tobago. Human Heredity 2005, 60:129-133.

39. Thompson IM, Pauler DK, Goodman PJ, Tangen CM, Lucia MS, Parnes HL, Minasian LM, Ford LG, Lippman SM, Crawford ED, et al: Prevalence of prostate cancer among men with a prostate-specific antigen level $<$ or $=4.0 \mathrm{ng}$ per milliliter. New England Journal of Medicine 2004, 350:2239-2246, [Erratum appears in N Engl J Med. 2004 Sep 30;351 (14):1470].

doi:10.1186/1750-9378-6-25

Cite this article as: McDonald et al: A case-cohort study of human herpesvirus 8 seropositivity and incident prostate cancer in Tobago. Infectious Agents and Cancer 2011 6:25.

\section{Submit your next manuscript to BioMed Central and take full advantage of:}

- Convenient online submission

- Thorough peer review

- No space constraints or color figure charges

- Immediate publication on acceptance

- Inclusion in PubMed, CAS, Scopus and Google Scholar

- Research which is freely available for redistribution

Submit your manuscript at www.biomedcentral.com/submit
C Biomed Central 